\title{
Emergencia del Sur Global. Perspectivas para el desarrollo de la periferia latinoamericana
}

\author{
Victor Ramiro Fernandez* \\ Carolina Teresita Lauxmann *** \\ Manuel Facundo Trevignani ${ }^{* * * * *}$
}

\begin{abstract}
Resumen
La periferia del sistema mundo - que denominamos en este trabajo "Sur Global" - ha experimentado un salto en su dinamismo durante la última década, liderado por un grupo de países, con epicentro en el Este asiático, convertidos en los principales dinamizadores del sistema. Ante la advertencia de ese particular contexto, y desde una perspectiva centralmente comparativa de las dinámicas de América Latina y el Este de Asia, en el presente trabajo se exploran algunos elementos que procuran dar cuenta del alcance de esa irrupción en cuanto a su potencialidad de alterar la estructura del sistema mundial y las posibilidades que, en dicho escenario, se abren para el desarrollo de la periferia latinoamericana.
\end{abstract}

Palabras-clave: Sistema-mundo; Sur global; Este asiático; Latinoamérica.

\begin{abstract}
Emerging Global South. Development perspectives for Latin-American periphery

The periphery of the world-system - the "Global South" for us - has experienced a jump in its dynamism over the last decade, led by a group of countries, centered in East Asia, that have become the most dynamic of the system. Given this particular context, and from a comparative perspective of the dynamics of Latin America and East Asia, this paper explores some elements that seek to notice the scope of this emergency in terms of its potential to alter the structure of the global system and the possibilities that, in this context, arises for Latin-American development.
\end{abstract}

Keywords: World-system; Global South; East Asia; Latin America.

JEL O10, P10.

\section{Introducción}

Diversos desarrollos teóricos dentro de la escuela del capitalismo histórico han dado cuenta de la existencia prácticamente inalterable de un sistema-mundo capitalista jerárquicamente organizado y desigual durante los últimos dos siglos

* Recibido el 13 de julho de 2012 y aprobado el 14 de dezembro de 2013.

** Investigador del Consejo Nacional de Investigación Científica y Tecnológica (Conicet) / Director del Instituto de Investigación Estado, Territorio y Economía (IIETE), Universidad Nacional del Litoral, Argentina. Email: rfernand@fcjs.unl.edu.ar.

*** Becaria doctoral del Consejo Nacional de Investigación Científica y Tecnológica (Conicet) / Investigadora del Instituto de Investigación Estado, Territorio y Economía, Universidad Nacional del Litoral, Argentina. E-mail: claux@unl.edu.ar.

**** Investigador del Instituto de Investigación Estado, Territorio y Economía, Universidad Nacional del Litoral, Argentina. E-mail: mtrevignani@hotmail.com. 
(Wallerstein, 2004), así como de la presencia de excepcionalidades que posibilitan cierta movilidad dentro de dicha estructura (Arrighi; Drangel, 1986; Arrighi et al., 2003; Mahutga, 2006). Sin embargo, a partir de la última década, parece haberse consolidado un diferencial dinamismo de países tradicionalmente periféricos, en el marco de la pérdida de poderío económico norteamericano, que habilita a plantear la posibilidad de alteración de dicha estructura y sus características de la mano de la progresiva emergencia del Sur Global ${ }^{1}$.

Identificar ese escenario no conlleva sostener la existencia o inminencia del "colapso" del dominio de Estados Unidos, como sostienen algunos autores (Dabat; Leal, 2013), ni negar la pervivencia de su liderazgo dentro del sistema-mundo, esencialmente en los campos político-militar, financiero e ideológico (Borón, 2008; Fiori, 2008; Medeiros, 2008). Tampoco implica reconocer un generalizado e inmediato descentramiento a favor de una nueva espacialidad históricamente postergada. No obstante, permite advertir la existencia de un cambio geoeconómico de gran magnitud o, en otras palabras, permite advertir la existencia de un proceso de cambios en las fuerzas dinamizadoras y tractivas del capitalismo que empodera a países históricamente periféricos, relegados dentro de la economía global.

Así, ante ese escenario de pervivencia de la jerarquía del sistema mundial, la emergencia del Sur como nuevo centro dinámico lleva a cuestionarnos sobre las posibles repercusiones que podrían tener en el orden global y, particularmente, cuáles son las posibilidades que se le presentan a América Latina ante ese nuevo escenario para salir de su situación periférica. Es decir, ¿cuáles son las potencialidades y limitaciones que presenta esa proyección del Sur para lograr revertir, o al menos atenuar, las formas asimétricas de subordinación y exclusión vigentes en el sistema-mundo que permitan a Latinoamérica alcanzar el desarrollo?

Para abordar el análisis de ese posible cambio en la configuración estructural del sistema-mundo y de las posibilidades que en ese contexto se abren para el desarrollo de América Latina, el presente trabajo se estructura en cuatro partes. En la primera parte, se recuperan y articulan diversos desarrollos teóricos relativos a la conformación jerárquica del sistema mundial y su dinámica de pervivencia, y se brinda información estadística que opera como soporte empírico complementario de aquellos. Asimismo, a partir de la consideración de ciertos desempeños excepcionales que han trasladado el centro dinámico de acumulación a

(1) En el presente trabajo, cuando se hace referencia al "Norte" o "países centrales", se considera incluidos dentro del mismo a Estados Unidos, Europa Occidental, Japón y los principales países de la Commonwealth. Por contraposición, bajo la denominación "Sur Global” o "países periféricos", se agrupa al resto de los países del sistema-mundo. Esa disquisición se encuentra relacionada con el nivel de ingreso medio de sus habitantes, considerado como indicador indirecto de la posición en la jerarquía de riqueza de un país dentro del sistema-mundo, cuestión sobre la que se profundizará en la primera parte del presente trabajo. 
la periferia, se introduce el interrogante acerca de la plausibilidad de alteración en la jerarquía del sistema-mundo.

En la segunda parte, en el marco del cambio geo-económico precitado, asociado al marchitamiento del poderío económico estadounidense en la escena global, el análisis se centra en la emergencia del nuevo polo dinámico de acumulación capitalista en el Este asiático, con China como actor de referencia central. Para ello se analizan ciertas dimensiones - como: a) participación en el PBI total; b) direccionamiento de los principales flujos comerciales; y c) la presencia de empresas transnacionales y los registros de patentes - que permiten identificar la presencia cuantitativa y cualitativa del nuevo centro dinámico dentro del escenario global.

En la tercera parte, se da cuenta, en primer lugar, del efecto traccionador que el desarrollo del Este asiático ha ocasionado en el resto de los países de la periferia del sistema-mundo - también en crecimiento - y de las consecuencias que ello ha traído aparejado en la generación de riqueza global con respecto al "Norte". En segundo lugar, se examina la dinámica interna del Sur Global sobre la cual se ha sustentado el crecimiento del bloque como un todo. Se pretende, con ello, considerar las potencialidades y/o limitaciones que presentan las formas de relacionamiento intra-bloque para procurar producir una alteración en la dinámica polarizante que ha caracterizado a la reproducción del sistema-mundo capitalista y, en ese contexto, viabilizar el desarrollo latinoamericano.

Por último, presentamos algunas consideraciones finales que resumen los resultados alcanzados y promueven líneas de investigación futuras para analizar la posición de América Latina en la reconfiguración que actualmente se encuentra atravesando el sistema-mundo capitalista.

\section{El sistema-mundo como unidad de análisis de la evolución del capitalismo histórico}

\subsection{La estructura jerárquica y su dinámica desigualadora}

La teoría del sistema-mundo desarrollada por Wallerstein (1974) ha sido objeto de múltiples críticas y revisiones (McMichael, 1990; Mintz, 1977; Roseberry, 1989; Skocpol, 1977; Tomich, 1990, 1991, 1997; Wolf, 1982). No obstante, su pretensión de explicar la estructura y dinámica de funcionamiento del sistema capitalista a partir de la concepción del mismo como una única economía integrada a escala planetaria sentó las bases para elaborar un estudio de las diferentes performances de las economías nacionales en una visión que trasciende 
los análisis Estado-céntricos ${ }^{2}$ y pone en consideración los procesos transnacionales - y sus correspondientes estructuras de poder - que operan obstaculizando o promoviendo el desarrollo de aquellas.

Así, la adopción del sistema-mundo - entendido como una economíamundo integrada por una única división internacional del trabajo y múltiples instituciones económicas, políticas y sociales ${ }^{3}$ - resulta útil como marco analítico para estudiar distintas especificidades y desempeños nacionales al considerar la organización jerárquicamente estratificada y la dinámica desigualadora de la economía mundial dentro de la cual aquellas tienen lugar.

La división internacional del trabajo única que conforma la economía mundial puede descomponerse en una serie de cadenas de mercancías que, articulando diversos sistemas productivos, traspasan las fronteras nacionales (Hopkins; Wallerstein, 1986; Wallerstein, 1974, 2004). Cada una de esas cadenas mercantiles está compuesta por distintas actividades integradas en el tiempo y en el espacio, que tienen como corolario la producción de bienes y servicios finales. El valor agregado por cada una de esas actividades y las formas de apropiación/retención del mismo permiten identificar: a) actividades centrales aquellas que absorben la mayor parte de los beneficios producidos dentro de la cadena; y b) actividades periféricas - las que sólo se apropian de una porción marginal del beneficio - y, a partir de ello, advertir la desigual apropiación de beneficios del intercambio internacional existente entre las mismas (Arrighi; Drangel, 1986; Wallerstein, 1974, 2004), que explican, en gran medida, la existencia de una estructura jerárquica y desigual.

En su evolución histórica de largo plazo, la economía-mundo capitalista ha experimentado transformaciones en esa división internacional del trabajo, fundamentalmente en los períodos de crisis del sistema-mundo (Hopkins; Wallerstein, 1986; Wallerstein, 1974, 2004). Se produce, de ese modo, una reestructuración periódica de tal división con el fin de hacer viable el continuo proceso de acumulación del capital. En otras palabras, se reorganiza el sistema para hacer posible su pervivencia como modo de acumulación a nivel global (Arrighi, 1999), es decir, para posibilitar la continua expansión y acumulación del capital a lo largo y a lo ancho del planeta (Fröbel et al., 1977; Harvey, 2004).

Pero ese proceso de constante reestructuración y transformación de la división internacional del trabajo, y de las distintas cadenas mercantiles que la componen, no ha importado, sin embargo, una modificación de las zonas en las que

(2) Dentro de esa perspectiva de análisis, pueden encuadrarse los estudios sobre los "Estados desarrollistas" del Este asiático que centran la explicación de la performance diferenciada de esos países en las particulares características de sus Estados (por ejemplo, Johnson, 1987; Evans, 1995; Woo-Cummings, 1999), desconsiderando los elementos del contexto internacional.

(3) Para mayor desarrollo ver: Wallerstein (2004). 
se localizan predominantemente las actividades centrales y/o periféricas y, por lo tanto, no ha incidido en la conformación de la estructura del sistema-mundo ${ }^{4}$.

Los procesos de reorganización implican prácticas de tipo schumpeterianas que llevan a la constante introducción de innovaciones, tanto a nivel de productos como de procesos y procedimientos, en las que intervienen los empresarios capitalistas, aunque también los Estados Nacionales (Pérez, 2004, 2009). Los agentes empresariales que se encuentran en mejores condiciones para llevar a cabo esa tarea son aquellos de las zonas centrales (Arrighi; Drangel, 1986). Por un lado, cuentan con la ventaja tecnológica de su estructura productiva, resultado del éxito anterior en los procesos de "destrucción creativa" (Arrighi; Drangel 1986). Por otro lado, disponen de Estados fuertes - con un importante aparato militar y administrativo burocrático (Skocpol, 1977), así como con un substancial poder infraestructural (Mann, 1984) -, que coadyuvan al proceso innovativo a través de una serie de beneficios extraeconómicos - por ejemplo, protección al desarrollo industrial, inversión en I+D, etc. (Arrighi; Drangel, 1986; Weiss, 2003).

Ya desde mediados del siglo XV, aunque con un menor alcance que la economía capitalista contemporánea - básicamente concentrada en Europa -, se advierte la existencia de una división internacional del trabajo segmentada de modo tal que da lugar a la apropiación diferencial de los beneficios entre los distintos países que la conformaban, permitiendo el establecimiento y la consolidación de la jerarquía de la economía mundial (Wallerstein, 2004).

La importancia relativa de cada zona o conjunto de países, y por ende la estructura jerárquica, ha permanecido prácticamente sin mayores variaciones a lo largo de toda la historia de la economía-mundo capitalista. Es más, con posterioridad a la Segunda Guerra Mundial al amparo de la hegemonía de Estados Unidos, incluso bajo la nueva división internacional del trabajo que comenzara a esbozarse en la década de los 70 s de la mano de la pérdida de su poderío económico, se ha profundizado la brecha que separa los países centrales de aquellos pertenecientes al Sur Global (Arrighi et al., 2003).

Siguiendo a Arrighi y Drangel (1986), puede considerarse al PBI per cápita como indicador indirecto y aproximado del mix de actividades que controla un determinado país dentro de las cadenas de mercancías globales. De ese modo, el Gráfico 1 da cuenta de las tendencias divergentes evidenciadas por ambos grupos de países en términos del ingreso medio percibido por sus habitantes y de un ritmo diferencial de crecimiento que, de mantenerse, incrementaría aún más la brecha entre el Norte y el Sur Global.

(4) El estado normal de cualquier sistema-mundo presenta una estructura jerárquicamente organizada, conformada en base a una dinámica que contribuye a mantener dicho orden a lo largo de tiempo. Ver Wallerstein (2004); Arrighi et al. (1986, 1990, 2003). 
Gráfico 1

Evolución del PBI per cápita en dólares internacionales de 1990 (1950-2001)

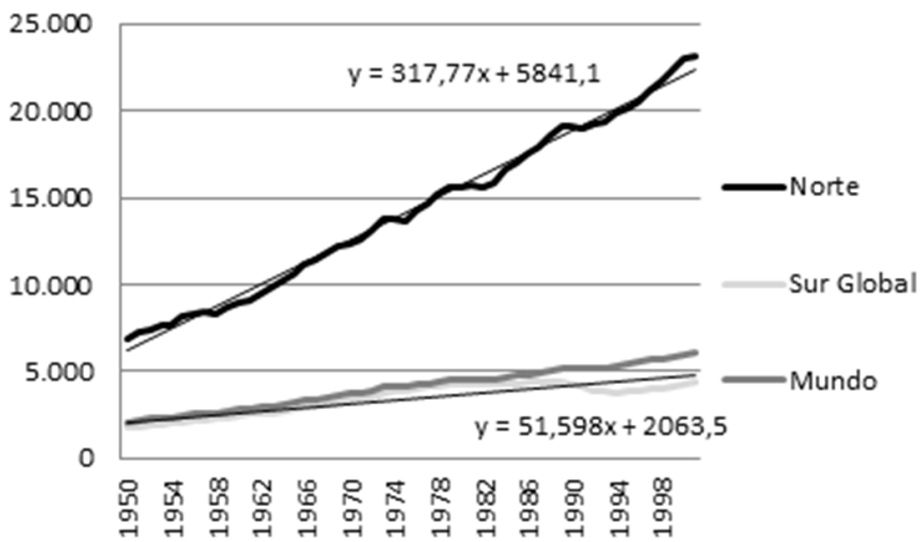

Fuente: Elaboración propia en base a datos de Maddison (2006).

La continuidad de esa estructura desigual del sistema-mundo capitalista se advierte hasta la actualidad. En el Gráfico 2, puede observarse que son relativamente pocos los países de alto nivel de ingreso (mayores a USD 25.000 por habitante), y los mismos pueden identificarse con la zona definida como "Norte". Por el contrario, en vastos espacios del globo, predominan los bajos niveles de ingreso per cápita, incluso llegando a valores muy inicuos, inferiores a los USD 2000 por habitante. De ese modo, se puede advertir la inalterabilidad del grupo de países que controlan las actividades de mayor valor agregado dentro de la cadena de mercancías, conformando las zonas centrales, y de aquellos que, por el contrario, quedan relegados al desarrollo de actividades periféricas y a la periferia del sistema mundial.

\section{Gráfico 2}

Distribución por rangos de PBI per cápita de los distintos países del sistema-mundo

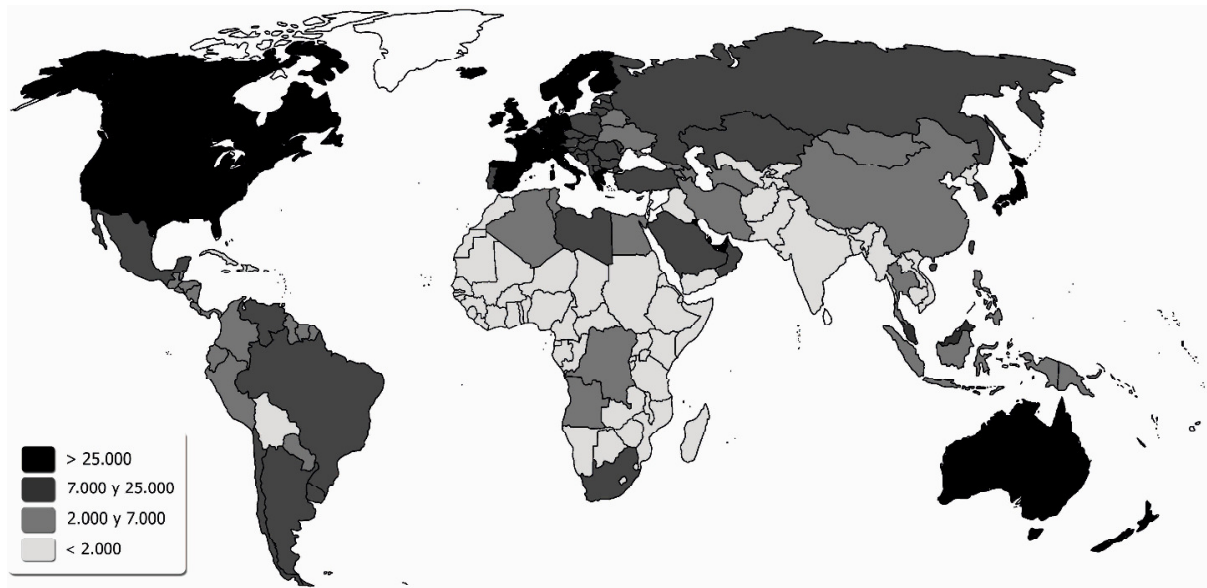

Fuente: Elaboración propia sobre la base UNCTAD (2012). 
Existen, también, otros indicadores a través de los cuales se puede abordar la inalterabilidad de la jerarquía del sistema-mundo.

En la economía contemporánea, las Empresas Transnacionales (ETs), que deslocalizadamente desarrollan las distintas actividades de una cadena de mercancía, son los agentes capitalista dinamizadores de la acumulación. La localización de las actividades centrales controladas por las ETs generalmente coincide con el lugar de origen o ubicación de la sede principal de las mismas. El análisis de su radicación resulta, entonces, útil como indicador indirecto de la estructura jerárquica del sistema mundial. En ese sentido, el Gráfico 3 permite observar la preeminencia de las grandes ETs de los países centrales por sobre los periféricos. La comparación de la cantidad de empresas transnacionales - entre las 100 más importantes a nivel mundial - con origen en el Norte y el Sur Global entre los años 1990 y 2008 denota la amplia disparidad existente entre ambas zonas, no obstante el crecimiento que las ETs del Sur han experimentado en ese interregno.

Por otra parte, la identificación de los centros generadores de innovación tecnológica - actividad central dentro de la cadena - y su distribución geográfica refuerza la tesitura de la pervivencia de la estructura jerárquica y su inalterabilidad. A ese respecto, el análisis de los países que concentran los mayores requerimientos de patentes también permite advertir que existe una amplia brecha que separa a los países centrales de los periféricos (Gráfico 4). Según la oficina de patentes de Estados Unidos, hacia finales de la última década, los países centrales contaban con el $90 \%$ de la cantidad de patentes presentadas, lo cual marca su claro predominio en lo que hace al desarrollo de conocimiento y tecnología a nivel mundial (USPTO, 2012), actividades que generan importante valor agregado y beneficios dentro de la cadena.

Gráfico 3

Distribución de las 100 principales ETs del mundo (1990-2008)

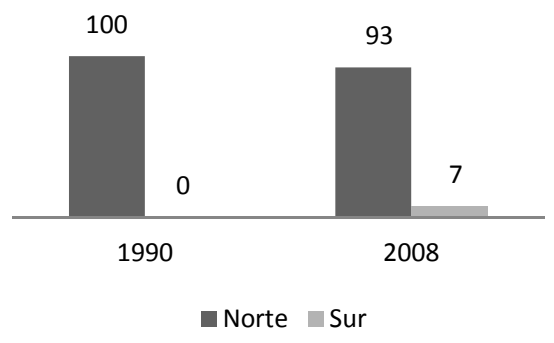

Fuente: Elaboración propia sobre la base Forbes. 
Gráfico 4

Solicitud de patentes (1990-2008)

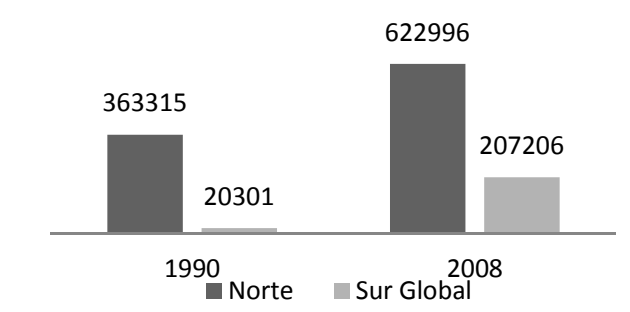

Fuente: Elaboración propia sobre datos del Banco Mundial.

\section{2 ¿Inalterabilidad en las jerarquías del sistema-mundo?}

Pese a ese contexto aparentemente inalterable en la estructura jerárquica, la división internacional del trabajo que comenzó a configurarse durante los '70 abrió ciertos interrogantes respecto a su perdurabilidad, al menos en su forma actual. Esa nueva división internacional del trabajo, resultado de las crisis cíclicas en las que se ve envuelto el sistema capitalista, fue considerada por algunos autores (Hardt; Negri, 2000; Harris, 1986; Robinson; Harris, 2000) como una posibilidad de revertir las jerarquías del sistema-mundo de la mano de una creciente industrialización de los países periféricos.

Esos planteos, que implícitamente identifican desarrollo con industrialización, pronto se enfrentarían con la realidad de que industrializarse no implica necesariamente desarrollarse (Arrighi et al., 2003; Amsden, 2001). En sí mismo, el avance en actividades manufactureras no supone mejorar el nivel de riqueza de la población. Las actividades de mayor valor agregado dentro de una cadena ya casi no se encuentran en la fase de producción propiamente dicha; ahora, la investigación y el desarrollo, el diseño, el marketing y la comercialización de los productos ocupan los puestos centrales en la generación y retención de valor (Breslin, 2005; Gereffi, 2001; Humphrey; Schmitz, 2000; Kaplinsky, 2000). La industrialización de muchos países periféricos no resultó condición suficiente para el mejoramiento de su posición dentro de la jerarquía de riqueza.

Resulta plausible, entonces, interpretar la relocalización de las actividades manufactureras y la nueva división internacional del trabajo a la que la misma dio lugar a la luz de los conceptos introducidos en el punto anterior. Estaríamos, por lo tanto, ante la presencia de una nueva reestructuración del sistema comandada por los capitalistas y Estados centrales a partir de la cual aún gran parte de la generación y apropiación del valor continúa concentrándose en el centro. 
Pero en la actual etapa del sistema capitalista, los agentes capitalistas centrales que dinamizan la economía mundial, las grandes Empresas Transnacionales (ETs), que ya mencionáramos, ya no sólo se benefician de la asociación con los Estados capitalistas centrales, bajo cuyo territorio tenían asentados prácticamente la totalidad de sus actividades, sino que aprovechan también las ventajas que ofrecen las distintas instancias nacionales - incluso aquellas que pertenecen a la periferia del sistema mundial.

Procurando elevar al máximo posible la ganancia obtenida en la producción y comercialización de mercancías a escala global (Dicken, 2007), las ETs internacionalizan y multilocalizan sus procesos productivos. Así, las actividades de menor valor agregado y nivel de sofisticación de la cadena que emplean abundante mano de obra se localizan en aquellas zonas que ofrecen condiciones más propicias para la utilización intensiva del trabajo (Fröbel et al., 1977), al mismo tiempo que garantizan la existencia de capital físico y ciertas "capacidades sociales" bajo la forma de la calificación de la mano de obra y la experiencia gerencial (Hikino y Amsden, 1995). Por el contrario, las actividades que generan y retienen mayor valor se localizan en las zonas centrales, que ofrecen mejores condiciones de infraestructura de servicios y un alto nivel de capacitación de mano de obra, indispensable para el desarrollo de dichas actividades (Sassen, 1998).

Esa dinámica de interacción entre las ETs y los diversos Estados nacionales, sobre la que se estructura la economía contemporánea, no ha procurado una modificación de la zona de radicación de actividades centrales y periféricas. Por el contrario, no ha hecho sino contribuir a la pervivencia de la estratificación jerárquica de la economía mundial. Por lo que no habría mayores expectativas de poder conformar un sistema mundial menos desigual. Sin embargo, es necesario advertir que ha sido precisamente en ese escenario que ciertos países tradicionalmente periféricos del Este asiático - Taiwán y Corea del Sur - han podido lograr un upgrading en su estructura productiva, comenzando a desarrollar y controlar actividades que generan y retienen alto valor agregado dentro de la cadena de mercancías (Amsden, 2001, 2003), logrando, a través de ello, posicionarse como centro dinámico de la acumulación capitalista a escala planetaria.

Si bien la estrategia de desarrollo de esos países estuvo orientada en un primer momento al estímulo de una estructura productiva competitiva internacionalmente en bienes de escaso valor agregado, aprovechando la abundante oferta de mano de obra barata, luego apuntó a un proceso de aprendizaje e 
innovación que permitió sofisticar el nivel de su producción (Amsden, 2003; Chibber, 2008; Hikino; Amsden, 1995; Li et al., 2012). Evolucionaron, así, hacia el desarrollo de actividades centrales dentro de las cadenas de mercancías, rompiendo con la predeterminación que implicaba su posición periférica al desarrollo de actividades de bajo valor agregado $\mathrm{y}$, de esa manera, lograron mejorar su participación en la apropiación de beneficio generado dentro de la misma. Es decir, se generó un quiebre en la dinámica desigual sobre la que se estructura el sistemamundo, que asocia a países centrales con actividades de alto valor agregado y a países periféricos con actividades de escaso valor. Ese grupo selecto de países periféricos comenzó a controlar algunas de las actividades que absorben la mayor parte de los beneficios producidos en las cadenas de mercancías, que, con anterioridad, eran de exclusivo dominio de los países centrales, y a dinamizar la acumulación del capital a escala global.

Indagar en la capacidad diferencial de esos países del Este asiático para romper con la estructura del sistema-mundo y convertirse en centros dinámicos de acumulación excede los límites del presente trabajo ${ }^{5}$. No obstante, es preciso señalar que en ese esquema de desarrollo han influido tanto factores endógenos como exógenos. Entre los primeros, adquieren relevancia central las trayectorias históricas de esos países, así como también las pautas de comportamiento y los valores que se desprenden de aquellas, generando determinadas estructuras de poder que se cristalizan en el aparato estatal y en sus particulares estructuras y estrategias de acción (Pempel, 1999; Woo-Cumings, 1999). En el segundo grupo factores exógenos - reviste importancia central el contexto geopolítico particular del orden bipolar en el que tuvo lugar su apertura a las corrientes de flujos internacionales (Glassman, 2011; Pempel, 1999).

Tanto unos como otros han permitido a los Estados de los países del Este asiático contar con cierta capacidad de condicionamiento y direccionamiento de la inversión extranjera (Wade, 2008; Chibber, 1999, 2008; Chang, 1993, 2004; Pempel, 1999). Esa posibilidad de establecer ciertas pautas para la penetración del capital foráneo les permitió, junto con el respaldo de una base de capital local altamente disciplinada, pasar de realizar funciones escasamente significativas - en términos de valor agregado - dentro de la cadena de mercancías a ejecutar actividades que generan y retienen mayor valor, desarrollando tareas más sofisticadas de producción, comercialización y diseño e incrementando su participación en la generación de riqueza global.

(5) El lector interesado puede recurrir, por ejemplo, a Chibber (1999, 2008); Evans (1995); Kohli (2009); Wade (2008); Weiss (2003) y Wo-Cumings (1999). 
Ahora bien, ese escenario de pervivencia del orden jerárquico y desigual del sistema-mundo, pero también de existencia de cambios en la fuerzas traccionadoras y dinamizadoras del capitalismo que empodera a países históricamente periféricos, presenta el siguiente interrogante: ¿es posible pensar un escenario más igualador sobre la base de una distribución más equitativa del valor generado en las múltiples cadenas de mercancías que conforman la división internacional del trabajo? A los efectos de procurar dar una respuesta, en el siguiente apartado, se analiza el crecimiento del Este asiático, cuyo dinamismo actualmente se encuentra encabezado por la economía china concomitantemente con el proceso de marchitamiento del poderío económico estadounidense a partir de la década de 1970, al que anteriormente hiciéramos referencia.

\section{El marchitamiento del poderío económico de Estados Unidos en la producción mundial y la emergencia y consolidación del nuevo centro dinámico de acumulación capitalista}

Como se mencionó en el apartado anterior, la nueva división internacional del trabajo emergente en la década de 1970 posibilitó, a través de la participación de las ETs y sus estrategias de relocalización, que ciertas etapas del proceso de producción se desplazasen hacia zonas tradicionalmente periféricas que le ofrecían condiciones más propicias para continuar con su reproducción que las zonas centrales.

En el marco de ese proceso de reestructuración global del capitalismo, se ha producido una relativización del poderío económico que Estados Unidos ha tenido desde fines de la Segunda Guerra Mundial concomitantemente con la emergencia del Este asiático como eje motorizador del proceso de reproducción del capital a escala planetaria. La pujanza de esa región, actualmente encabezada por China, se monta en una dinámica de bloque que reconoce sus inicios a mediados del siglo XX con la incorporación de Japón dentro de los países líderes de la economía mundial y que, luego, a partir de la nueva división internacional del trabajo, referenciada en el punto anterior, fue continuada por países como Taiwán y Corea del Sur.

El dinamismo de ese bloque puede observarse en el Gráfico 5, que da cuenta de la diferencial tasa de crecimiento de ciertas economías del Este asiático desde mediados del siglo XX, con valores mucho más elevados que el promedio mundial y que el de los EE.UU - incluso en la fase de consolidación de su hegemonía y de mayor apogeo a escala planetaria. 
Tasas de crecimiento del PBI (1950-1970, 1971-2001)

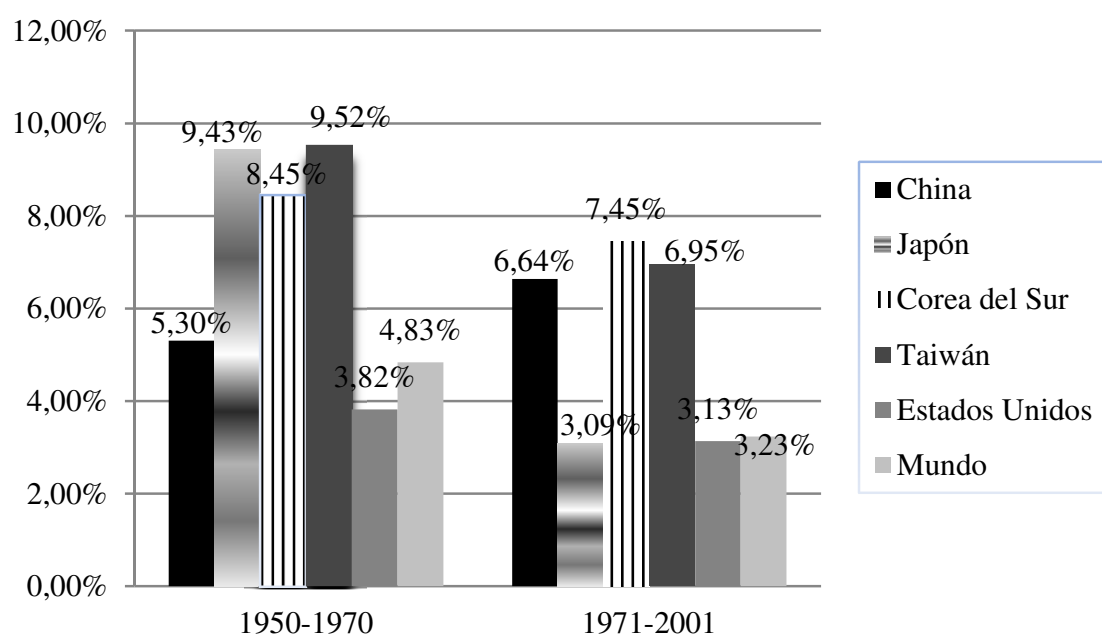

Fuente: Elaboración propia sobre la base de datos Maddison (2006).

El análisis del upgrading de la estructura productiva de esos países y de su mejora en el posicionamiento dentro de la jerarquía mundial implicaría un estudio desagregado de las cadenas de mercancías en las que participan, y del valor generado y apropiado por las distintas actividades que desarrollan, cuestión que resulta prácticamente inabarcable.

No obstante, a continuación se presenta una serie de indicadores: a) participación en el PBI total; b) direccionamiento de los principales flujos comerciales y contenido de los mismos; y c) control de las actividades centrales a través del análisis del lugar de origen de las ETs y de los principales centros de registración de patentes que, a pesar de evidenciar ciertas falencias para captar la naturaleza de los procesos de producción a escala planetaria, nos permiten avanzar en ese sentido. A partir de los mismos, podemos explorar la situación de potencial mejora que detenta ese grupo de países asiáticos en la generación y apropiación de riqueza a escala global, particularmente considerando el desempeño de la actual economía líder de la región asiática, China, en términos comparativos con la "debilitada" economía estadounidense, que dinamizara la acumulación durante la edad de oro del capitalismo.

\subsection{Participación en la generación de riqueza global}

Como puede observarse en el Gráfico 6, Estados Unidos ha mermado su participación en el PBI mundial. A pesar de que los porcentajes estadounidenses han presentado oscilaciones a lo largo del período analizado, no han podido restablecer los niveles conseguidos con anterioridad a la crisis del '70, cuando su cuota en el producto global era superior al 35\%. A su vez, hacia fines de la primera 
década del presente siglo, su participación alcanzó los mínimos históricos, explicando aproximadamente el $25 \%$ de la producción global.

En contrapartida, el Este asiático comenzó a incrementar su presencia en el PBI global a partir del crecimiento de Japón y de la sofisticación de su estructura productiva - que permitió su incorporación a los países centrales del sistemamundo durante el período de consolidación de la hegemonía estadounidense como ya mencionáramos en el punto anterior. Ese proceso fue continuado por países como Taiwán y Corea del Sur y, actualmente, se encuentra motorizado por China, con una incidencia en el PBI global que se aproxima al 10\% (Gráfico 6).

Gráfico 6

Evolución de la participación en el PBI Total (1970-2010) -dólares a precios corrientes

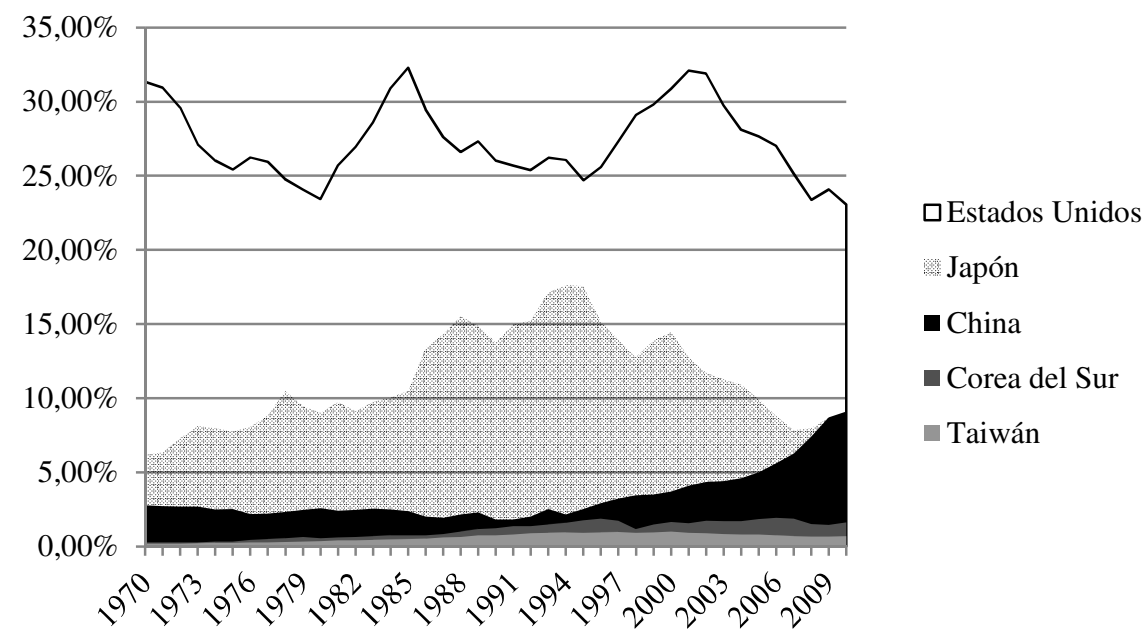

Fuente: Elaboración propia en base a datos de UNCTAD (2012).

La creciente participación de la economía china pareciera sustentarse, al igual que en el caso de los anteriores países que han ido conformando el centro dinámico de acumulación que desde el Este asiático relevara a Estados Unidos de esa posición dentro de la economía mundial, en un proceso de progresivo upgrade de su estructura productiva, que le ha permitido escalar gradualmente en las cadenas de mercancías (Li et al., 2012). No obstante, es preciso señalar que, aun, a pesar de su rápido crecimiento y la progresiva sofisticación de su economía, China todavía se encuentra a una considerable distancia respecto a Japón y el resto de los países asiáticos mencionados, en lo que hace a valor agregado generado internamente (Kwan, 2002).

\subsection{Direccionamiento de los principales flujos comerciales e identificación de sus principales características}

A partir del análisis de la balanza comercial de Estados Unidos de los primeros años del siglo XXI, se puede observar que el déficit ha aumentado año 
tras año con cada uno de sus socios comerciales más importantes, destacándose el crecimiento exponencial que ha tenido el correspondiente a China ${ }^{6}$. La deuda comercial con el gigante asiático ha alcanzado un récord histórico de 273 billones de dólares en el año 2010, cifra incluso superior a la suma de todos los déficits juntos que existen con los otros tres socios más grandes del país norteamericano: Japón, Canadá y México (Gráfico 7).

Gráfico 7

Evolución de los principales déficits comerciales de Estados Unidos (2002-2006) millones de dólares

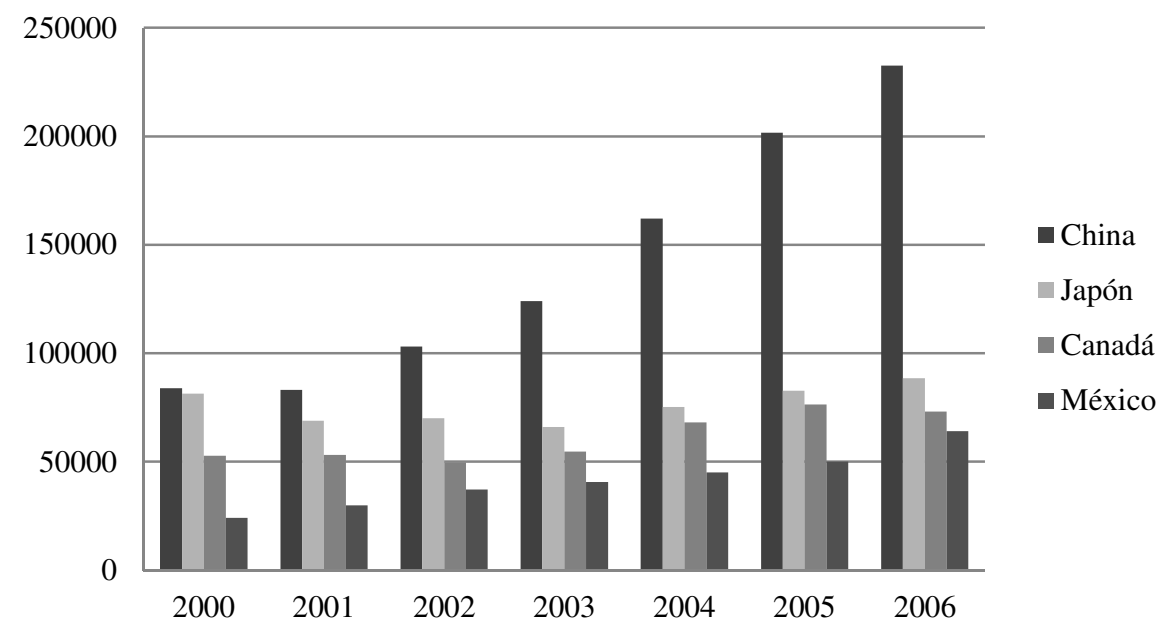

Fuente: Elaboración propia en base a datos de la United States International Trade Commission.

La magnitud del déficit comercial que Estados Unidos mantiene con China puede explicarse, en parte, por la progresiva incursión del país asiático en el mercado global a partir de las reformas económicas aperturistas introducidas desde finales de la década del setenta ${ }^{7}$. Essas reformas, realizadas en el contexto de la nueva división internacional del trabajo y la relocalización de la producción manufacturera, sentaron las bases para el ingreso de capital extranjero

(6) En ese punto es importante considerar, también, la importancia de China a nivel mundial. Según estadísticas de la OMC (2012), la economía china es considerada la mayor exportadora del mundo, con un volumen de 1578 miles de millones de dólares, superando a Estados Unidos - 1278 miles de millones - y a Alemania - 1269 miles de millones -, potencias que han detentado el liderazgo en ese rubro desde mediados del siglo XX.

(7) Dichas reformas fueron llevadas adelante por Deng Xiaoping en el año 1979 con el objetivo de transformar la estancada economía china en una economía de mercado a partir del ingreso de inversión extranjera, la habilitación para la creación de empresas privadas y el levantamiento de controles de precios y políticas proteccionistas, entre otras medidas. Esas reformas desembocaron en el ingreso definitivo a la OMC en 2001 luego de años de negociaciones (Dunford; Li, 2010; Beeson, 2009). 
aprovechando la existente y abundante mano de obra disponible, posicionándola como la "fábrica del mundo".

Para dimensionar la relevancia que han adquirido los países dinámicos del Este asiático, y en especial China como principal socio comercial de Estados Unidos, resulta conveniente contextualizar las importaciones chinas con relación al total de las importaciones realizadas por la potencia del Norte. En ese sentido, resultan útiles los datos proporcionados por la OMC (2012), según los cuales, para el año 2010, aproximadamente el 25\% de las importaciones de Estados Unidos procedieron de esos países del Este de Asia - siendo el $80 \%$ de dicho porcentaje explicado por China - el 26\% correspondió a sus socios de América del Norte, el $18 \%$ tenía origen europeo, mientras que América del Sur y África sólo representaban el 7\% y el 4\% de las importaciones, respectivamente (OMC, 2012).

A su vez, la vinculación comercial entre esos países asiáticos y Estados Unidos no sólo se ha estrechado en términos cuantitativos, sino que también ha mutado en términos cualitativos, en tanto los principales productos exportables al mercado norteamericano poseen mayor grado de sofisticación. Tomando a China como referencia por ser el principal exportador mundial a los Estados Unidos, el Gráfico 8 permite dar cuenta que en el año 2010 más de la mitad del total de exportaciones chinas a Estados Unidos se concentraron en dos rubros: Maquinaria y equipos eléctricos - representando aproximadamente el $30 \%$ del total exportado - y Equipos de generación de energía (28\%), ambas con una alta composición de valor agregado en sus productos. Mientras que para finales de la década del '90, si bien el rubro de maquinaria eléctrica y equipos era el de mayor participación relativa (25\%), más del $60 \%$ de las exportaciones chinas a Estados Unidos correspondían a actividades de baja sofisticación como juguetería y equipos deportivos (22\%), indumentaria (21\%) y calzados (18\%) (USITC, 1997; 2010).

De esa manera, en tanto décadas atrás la inserción de China en el mercado mundial estaba ligada al desarrollo de actividades de mano de obra intensiva y de bajo valor agregado dentro de la cadena, actualmente su capacidad industrial ha evolucionado hacia una progresiva sofisticación de sus actividades, conforme incorporan más contenidos tecnológicos, generando mayor valor agregado. A pesar de que China no desarrolla por completo la producción de los productos de mayor valor agregado dentro de sus fronteras e importa aún gran cantidad de los componentes de los bienes que fabrica, muchos de los cuales tienen como objeto alimentar las nutridas exportaciones a las que estamos haciendo referencia, en las últimas décadas, ha mostrado una gran mejora en su estructura productiva (Li et al., 2012). 
Gráfico 8

Principales exportaciones Chinas a Estados Unidos 2010

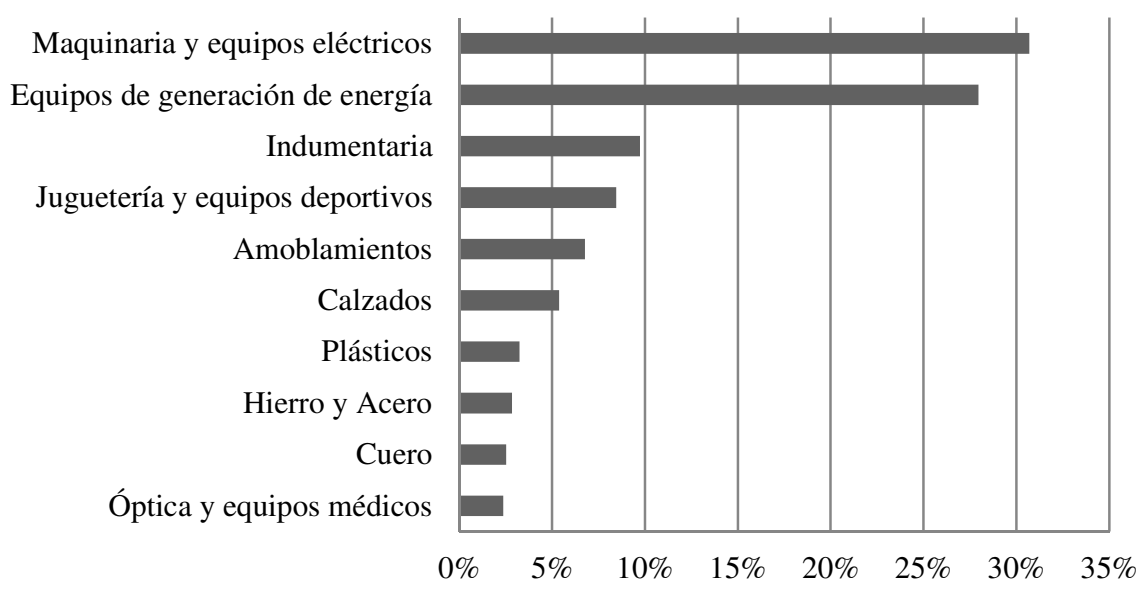

Fuente: Elaboración propia en base a datos de la United States International Trade Commission.

Finalmente, consideramos necesario resaltar que esa dinámica de crecimiento de China se produce concomitantemente con cierta pérdida de competitividad de la potencia hegemónica norteamericana en la producción mundial (Bergesen; Sahoo, 1985; Arrighi, 1999; Dabat; Melo Martínez, 2008; Dabat, 2009), al menos en las etapas de las cadenas estrictamente productivas - de menor valor agregado - situación que se ve reflejada en el creciente déficit de su balanza comercial. Vemos así que la estrategia de deslocalización de las ETs de origen estadounidense, para continuar con el proceso de valorización del capital en los términos más ventajosos posibles en el contexto de la actual economía globalizada, da cuenta, en gran medida, de la pérdida de dominio de la potencia del Norte en las actividades netamente de producción de las cadenas.

\subsection{Participación en las cadenas de mercancías. Una aproximación a través de las empresas transnacionales y los registros de patente}

Si bien la participación de China en las actividades centrales de las cadenas parece aún incipiente (Lemoine; Ünal-Kesenci, 2004), la creciente gravitación de empresas de ese origen dentro de las principales transnacionales del mundo da muestras de la tendencia a lograr una inserción cualificada dentro de las redes de producción e intercambio global.

Como se mencionara en el segundo punto del apartado precedente, la sede principal o lugar de origen de las ETs, actores líderes del proceso de acumulación en la actual fase del capitalismo, pueden considerarse como un indicador indirecto respecto del control de actividades de mayor valor agregado - centrales - dentro de 
una determinada cadena de mercancías, por considerar que allí también se llevan a cabo las mismas. Si se analiza la evolución de las empresas pertenecientes a Estados Unidos y a los países dinámicos del Este asiático dentro de las principales compañías transnacionales del mundo, se puede observar la creciente participación que han tenido estas últimas, principalmente las de origen chino, en las posiciones de liderazgo de la economía mundial.

A pesar de que las empresas estadounidenses representan la gran mayoría de las principales ETs, el Gráfico 9 pone en evidencia la pérdida de importancia que éstas han experimentado a nivel mundial entre 2005-2011. Asimismo, da cuenta del ritmo con el que viene incrementándose la participación de las empresas con origen tanto en China como en el resto de los países del Este asiático dentro de las 500 principales de la economía global, a excepción de Japón, que redujo su participación de 81 a 68 en ese período (Fortune, 2012).

Gráfico 9

Evolución de la participación de las empresas transnacionales de los países dinámicos del Este asiático y Estados Unidos dentro de las 500 principales (2005-2011)

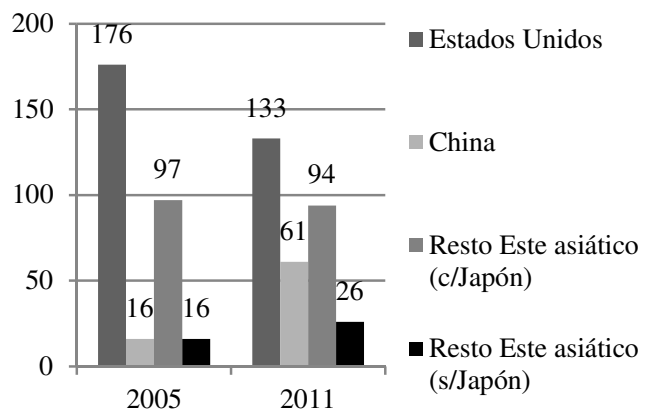

Fuente: Elaboración propia en base a datos de Fortune (2012).

Gráfico 10

Evolución de la solicitud de patentes en los países dinámicos del Este asiático y Estados Unidos (1985-2011)

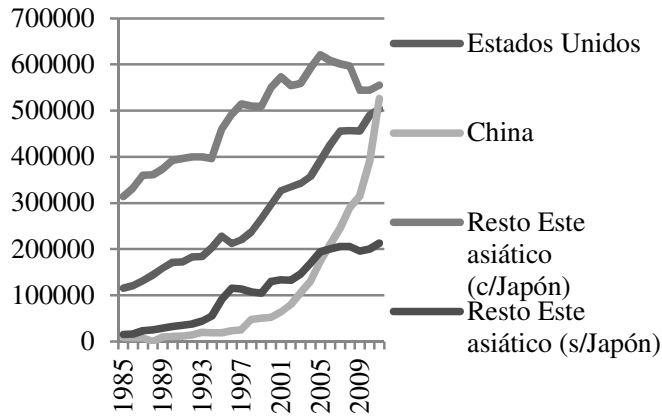

Fuente: Elaboración propia sobre datos del Banco Mundial (2012). 
Lo mismo puede advertirse al analizar el número de patentes registradas en el los países asiáticos durante los últimos 25 años - si bien Estados Unidos, en ese caso, también mantiene cierta superioridad - (Gráfico 10). El incremento de los pedidos de patentamiento de desarrollos tecnológicos -particularmente en China donde crecen exponencialmente - da cuenta de un creciente desarrollo de actividades - centrales - innovativas de importante generación y retención de valor agregado en los países asiáticos.

En suma, el análisis de los indicadores expuestos en los puntos 2.1, 2.2 y 2.3 nos permite dar cuenta de que si bien China aún no ha logrado mejorar su status dentro de la jerarquía de riqueza, como sí lo hicieran los antecesores asiáticos que iniciaron el relevo de Estados Unidos como centro dinámico de acumulación del sistema-mundo capitalista, el crecimiento de su economía se encuentra asociado a la sofisticación de su estructura productiva, incorporando crecientemente tecnología de punta la misma. Ese upgrading ofrece un horizonte promisorio para los países asiáticos cuyo dinamismo, actualmente motorizado por China, pareciera mantenerse sobre la senda del desarrollo de actividades centrales dentro de las múltiples cadenas de mercancías que componen la división internacional del trabajo.

El desempeño excepcional de esos países del Este de Asia, convertidos en centros dinámicos de acumulación de la economía-mundo actual, los ha habilitado a lograr movilidad ascendente dentro de la jerarquía de riqueza, pero ¿cuáles son las posibilidades que ésas prácticas se generalicen y puedan alcanzar reversivamente el histórico condicionamiento de la periferia al desarrollo de actividades de bajo valor agregado? En otras palabras, ¿en qué medida el dinamismo del Este asiático abre compuertas para la conformación de un escenario global más equitativo? Particularmente, ¿cuáles son los "espacios de esperanza" ${ }^{8}$ que se abren para la periferia latinoamericana?

\section{El Sur Global, su dinámica y la posibilidad de cambios en la estructura del sistema-mundo capitalista}

Para dar respuesta a los interrogantes últimamente formulados, resulta pertinente analizar: a) la particular tracción del Este de Asia sobre el dinamismo del Sur Global y su convergencia con el Norte, así como b) las relaciones que tienen lugar al interior del Sur y las limitaciones/potencialidades que esas presentan para el desarrollo de América Latina.

(8) En referencia al título que inspira la reconocida obra de David Harvey (2000). 


\subsection{Relaciones Sur-Sur y su convergencia con el Norte}

De acuerdo a lo desarrollado en el punto precedente, puede observarse que ciertos países del Este asiático, actualmente motorizado por China, se han posicionado como el centro dinámico de acumulación capitalista a escala planetaria. Desde ese particular posicionamiento, han estimulado el crecimiento del resto del mundo, particularmente de los países pertenecientes al Sur Global, con quienes han estrechado vínculos comerciales y financieros.

En términos de relaciones comerciales, se puede observar un fuerte incremento de las transacciones entre los países dinámicos asiáticos, África y América Latina, constituyendo actualmente la fuente de crecimiento del comercio mundial. Según estimaciones de la CEPAL (2010), es la primera vez en la historia del sistema capitalista que las vinculaciones comerciales entre países periféricos denotan tal densidad y dinamismo. Mientras que para mediados de los ochenta el intercambio Sur-Sur era de sólo el 6\% del comercio mundial, en 2010 dicha cifra se eleva a $24 \%$ y, si se toma en cuenta que la comercialización entre las economías avanzadas decayó del $63 \%$ al $38 \%$ en el mismo período, no resultaría extraño imaginar que el comercio entre los países periféricos pronto superará al intercambio entre los países centrales (CEPAL, 2011a).

En lo que respecta a los flujos financieros, a partir de la última crisis, en 2008, los países del Sur Global han ganado terreno en cuanto a captar grandes cuantías de inversión extranjera directa (IED). Pero, a su vez, y respondiendo a su implicación en el dinamismo del proceso de acumulación capitalista, se han consolidado no sólo como receptores, sino que han incrementado su rol como emisores de la misma.

Los países tradicionalmente periféricos, y con múltiples déficits en su conformación para atraer el capital, pasaron a captar, para el año 2010, más de la mitad de las entradas de IED mundiales. China ha sido el país que más capital extranjero ha atraído, seguido por India, mientras que Brasil y México se encuentran en el sexto y decimonoveno puesto, respectivamente, siendo los receptores más importantes dentro de América Latina (CEPAL, 2010).

Por otra parte, en lo que respecta a la IED proveniente del Sur Global, ésa ha incrementado sus volúmenes, adquiriendo mayor protagonismo en la escena mundial - de una participación del $5 \%$ en 1990 sobre el total de la IED mundial pasó a representar, en 2010, el 25\% de la misma. El dinamismo del Este asiático ha tenido mucho que ver en ese desarrollo, llegando a contribuir, en 2010, en un $66 \%$ del total de la IED del Sur, siendo China ${ }^{9}$ el país con mayor participación relativa (30\%) (UNCTAD, 2012).

(9) China invierte la mayor cantidad de dinero dentro de su continente. No obstante, América Latina ya se sitúa a la vanguardia de los destinos de IED del país asiático, aunque también África ha comenzado a ser un importante destino de sus excedentes, principalmente Sudáfrica (Santiso, 2008). 
A su vez, ese crecimiento de la IED del Sur ha estado orientado particularmente hacia la periferia del sistema-mundo. Como puede observarse en el Gráfico 11, si bien la cuantía de la inversión de países del Sur Global ha experimentado un considerable incremento hacia ambos bloques - Norte y Sur -, en el período 1995-2003, dicho indicador se ha triplicado en el caso de los países periféricos, lo que pone de manifiesto el estrechamiento de la vinculación Sur-Sur.

\section{Gráfico 11}

Evolución de la IED de empresas del Sur Global por bloque de destino en millones de dólares ॠIED en países del Sur Global $\quad$ IED en países del Norte 45000

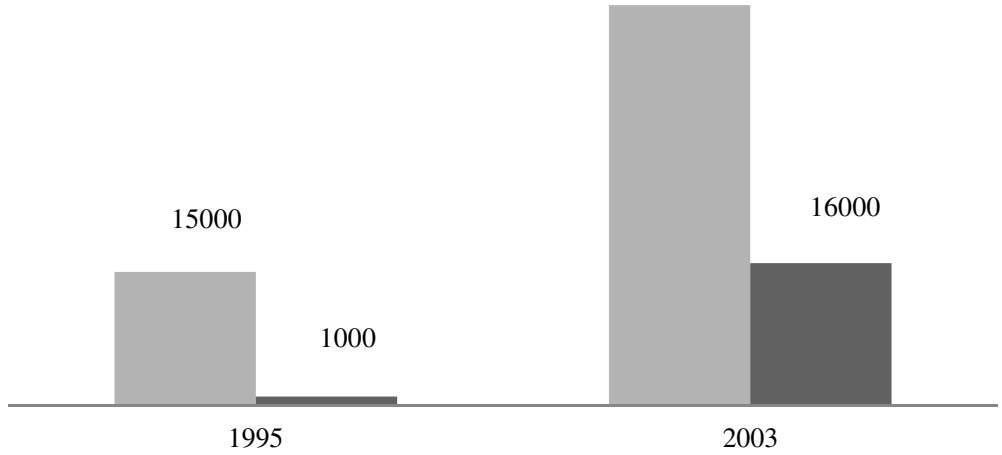

Fuente: Elaboración propia en base a datos de CEPAL.

En ese contexto, el fortalecimiento de los vínculos comerciales y financieros que comienza a configurarse entre los distintos países del Sur prefigura un escenario favorable para fortalecer aún más los vínculos económicos existentes.

Ahora bien, esa mayor relación tanto a nivel comercial como financiero entre los países del Sur tiene lugar sobre la base de un fuerte crecimiento económico de los diversos países que lo integran - particularmente los del Este de Asia. En los últimos años, las economías del Sur Global presentaron tasas de crecimiento del PBI muy superiores a las alcanzadas por los países desarrollados Norte -, tal como se puede observar en el Gráfico 12, donde se comparan ambos desempeños en relación al promedio mundial ${ }^{10}$.

(10) Muchos analistas estiman que esas tasas de crecimiento diferenciadas entre el Norte y el Sur se mantendrán hasta el año 2020. Por ejemplo, Naciones Unidas estima un incremento promedio anual del PBI, entre 2013 y 2020, del 2,5\% para los países del Norte y del 5,6\% para los países del Sur, mientras que el FMI y la OCDE proyectan tasas aún mayores para el Sur (CEPAL, 2012). 
Gráfico 12

Tasas de crecimiento del pbi por bloque de países (2009-2012)

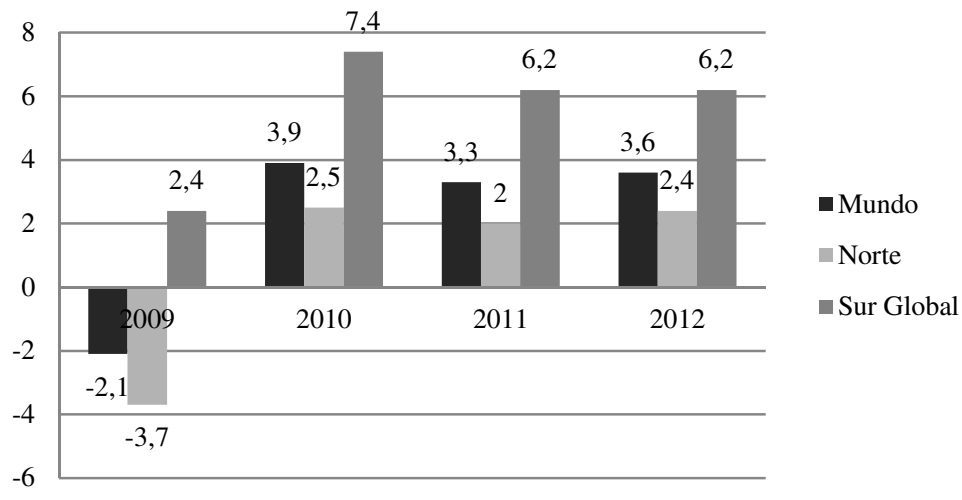

Fuente: Elaboración propia en base a datos de CEPAL.

Ese proceso de dinámico crecimiento que evidencian los países del Sur, con tasas que superan a la de los países centrales, resulta en un escenario de igualación con respecto al Norte en términos de la aportación al valor generado en la economía mundial. El Gráfico 13 permite dar cuenta de ello. Como resulta del mismo, la participación en el PBI total del Norte y del Sur Global ha permanecido prácticamente estable durante las últimas dos décadas del siglo $\mathrm{XX}$. En ese interregno, las economías centrales explicaban aproximadamente el $70 \%$ de la riqueza global, mientras que la participación de las economías periféricas alcanzaba apenas el 30\% restante. Sin embargo, para el año 2010, y en un proceso que reconoce sus inicios a principios del siglo XXI, dichos porcentajes tendieron a una marcada convergencia, situándose en el 53\% y el $47 \%$, respectivamente.

\section{Gráfico 13}

Evolución de la participación en el PBI global por bloque de países dólares paridad poder adquisitivo 2005

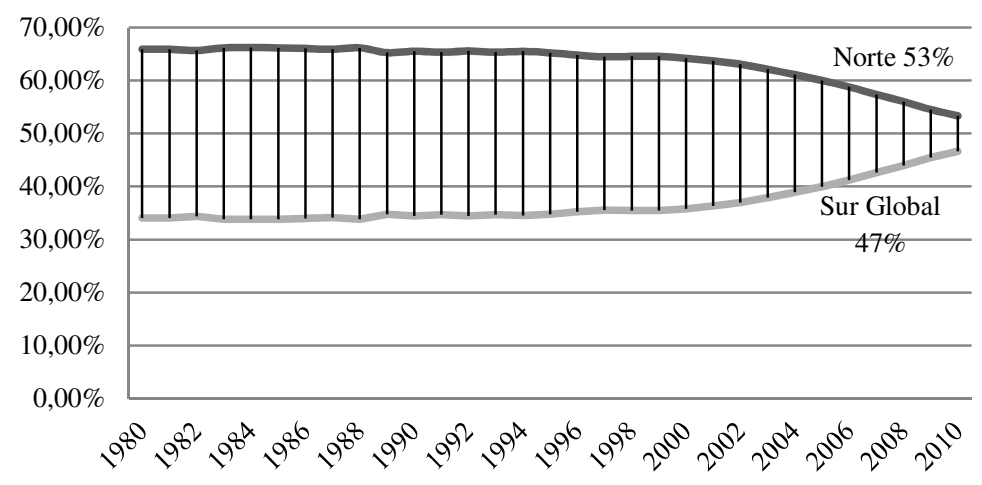

Fuente: Elaboración propia sobre la base de información del Banco Mundial. 


\subsection{Especificidades de la relación Sur-Sur}

En el punto anterior hemos expuesto que el Sur Global como un "todo" comienza a evidenciar una tendencia convergente con los países centrales en los últimos años en términos de su participación en la producción mundial. No obstante, también hemos resaltado la particular tracción ejercida por los países dinámicos del Este asiático en ese proceso de convergencia. Por lo tanto, en ese punto, reconociendo que el dinamismo del Este de Asia estimuló el crecimiento del resto del Sur, nos proponemos indagar las potencialidades y limitaciones que el estrechamiento de las relaciones con el bloque asiático supone para el desarrollo de América Latina.

En el marco de la emergencia del Sur Global, tanto América Latina como el Este asiático se han mostrado como sus dos bloques más dinámicos, pero los países asiáticos han evidenciado un desempeño ampliamente superior a la performance latinoamericana, como resulta del Gráfico 14.

Gráfico 14

Tasa de crecimiento del PBI per cápita, por bloque (1971-1990 y 1991-2010)

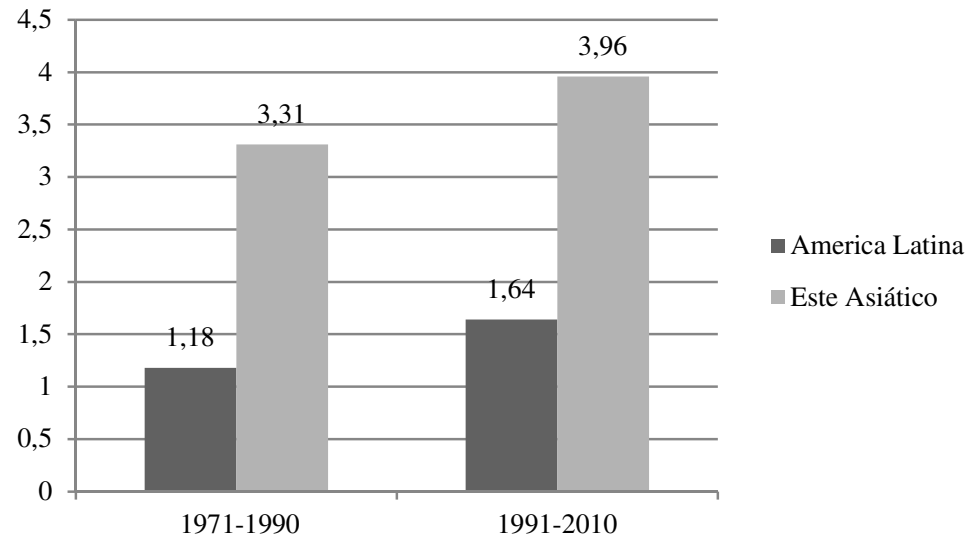

Fuente: Elaboración propia sobre la base de datos de Maddison (2006) y UNCTAD (2011).

A continuación, se analizan con algunas dimensiones que, permitiendo identificar su forma de inserción en las cadenas globales de mercancía, pueden ayudar a desentrañar esa performance diferenciada entre ambos bloques, así como los condicionamientos y/u oportunidades que las relaciones Sur-Sur suponen para el desarrollo de América Latina.

\subsubsection{Intercambios comerciales. Una aproximación desde la estructura productiva de los principales bloques del Sur Global}

Luego de la crisis del `70 y el consecuente fin de la edad de oro capitalista, la mayoría de los países periféricos liberalizaron sus mercados promoviendo la 
captación de inversión extranjera directa (IED) y promocionando las exportaciones en el marco de la nueva división internacional del trabajo. Sin embargo, no todos los países han seguido la misma estrategia para lograr la adaptación ante ese nuevo escenario global.

Los países del Este asiático que han encabezado el traslado del centro dinámico de acumulación hacia la periferia - Japón, Corea del Sur y Taiwán adoptaron una apertura gradual y selectiva de sus economías, en la cual el Estado $^{11}$ tuvo un rol activo, direccionando, articulando y supervisando los procesos de desarrollo hacia afuera, lo que dio lugar a una sofisticación creciente de sus estructuras productivas, que les permitió insertarse por las vías altas en las redes globales (Palma, 2010). Ese rol central que el Estado tuvo en la consecución del desarrollo asiático es considerado como la principal causa de éxito en la rápida expansión económica de la región (Amsden, 2001; Beeson, 2009; Akyuz et al., 1998). Para el caso de China, país que actualmente comanda el crecimiento del centro dinámico de acumulación del Este asiático, si bien las características "desarrollistas" de los Estados de Japón, Corea del Sur y Taiwán no se presentan de manera tan clara ${ }^{12}$, la creciente participación que ha adquirido en el control de actividades estratégicas dentro de las cadenas de mercancías, como vimos en la última parte del punto dos, permiten advertir un posible mejoramiento de su forma de inserción dentro del sistema-mundo (Beeson, 2009) y de su posicionamiento dentro de la jerarquía de riqueza.

En contrapartida, los países latinoamericanos, con sus especificidades, sufrieron el desmantelamiento de los distintos mecanismos de intervención del Estado en la economía y adoptaron las leyes del laissez faire bajo las recetas que impuso el denominado "Consenso de Washington" (Bresser Pereira; Gala, 2010; Palma, 2010), lo cual tendió a una progresiva desarticulación y reprimarización del tejido productivo industrial (Arceo, 2005), atentando contra formas de inserción cualificadas a las redes del comercio mundial. Puede considerarse que el efecto más positivo - sino el único - de la estrategia de adaptación de América Latina a la nueva división internacional del trabajo ha sido el incremento de sus

(11) No obstante el distinto grado de credibilidad y eficacia con el que ha sido llevado adelante por cada uno de los países (Amsden, 2001; Beeson, 2009; Wade, 2008).

(12) El Estado Chino, a diferencia de los Estados desarrollistas (Evans, 1995; Kohli, 2009, WooCumings, 1999) de los países que anteriormente han motorizado el crecimiento en el Este de Asia, presenta ciertas falencias en términos de sus estructuras y capacidades estatales, que ya por falta de coherencia interna, reclutamiento meritocráctico, falta de autonomía o de capacidad de enraizamiento en la sociedad, pueden llegar a condicionar/restringir la estrategia de crecimiento sobre la base del upgrade de su estructura productiva. 
exportaciones ${ }^{13}$, creciendo por sobre la media mundial desde los años noventa por primera vez en los últimos cincuenta años.

Pero, incluso ese indicador queda opacado cuando se lo compara con el registrado en los países dinámicos del Este de Asia. La tasa de crecimiento promedio anual de las exportaciones de América Latina en el período 1990-2010 fue del $10 \%$, cifra que, si bien es superior a la alcanzada por los países centrales $(6 \%)$, resulta inferior al $12 \%$ registrado por el Este asiático en el mismo período (UNCTAD, 2012).

Por otra parte, al analizar la composición de las exportaciones entre América Latina y el Este asiático, se observan patrones de intercambio diferentes, que dan ciertos indicios respecto a las particularidades de las estructuras productivas de las que surgen los productos exportables. En ese sentido, en el año 2010, las exportaciones latinoamericanas al Este asiático presentan un carácter fuertemente primario agro-exportador, mientras que, en las exportaciones de los países del Este asiático, los bienes manufacturados ocupan un lugar preponderante. Las exportaciones de materia prima desde América Latina al Este de Asia fueron de 85 mil millones de dólares, mientras que las de productos manufacturados alcanzaron un valor de $10 \mathrm{mil}$ millones. Por el contrario, las exportaciones de productos manufacturados del Este asiático hacia América Latina rondaron los 126 mil millones de dólares, en tanto las de materia prima no alcanzaron siquiera los 8 mil millones de dólares (UNCTAD, 2012).

La actual estructura exportadora latinoamericana se muestra, así, altamente dependiente de los productos primarios y manufacturas basadas en recursos naturales - el $70 \%$ exportado corresponde a ese tipo de bienes -, lo que denota la falta de evolución en el desarrollo y control de actividades de mayor valor agregado.

En ese sentido, se advierte que América Latina, a diferencia de lo que ha ocurrido en el cúmulo de países dinámicos del Este asiático que lograron movilidad ascendente dentro de la jerarquía de riqueza, continúa ante el desafío de modificar su forma de inserción en la economía mundial sobre la base de cualificar su estructura productiva y sofisticar su producción.

(13) Cabe aclarar que, en estos resultados, ha tenido una gran influencia los logros de algunos países, México particularmente, quien ha aprovechado el acceso a los mercados de América del Norte (Sánchez Ancochea, 2005). Asimismo, ha resultado particularmente importante para esa dinámica de crecimiento de las exportaciones, principalmente desde inicios del nuevo siglo, el crecimiento de los precios de los productos primarios comercializados por la región, tirados por la creciente demanda asiática (CEPAL, 2012). Las cifras muestran que, para América Latina, en promedio, los precios acumularon una suba de 20 puntos porcentuales superior a las cantidades (Berrettoni; Polonsky, 2011). 


\subsubsection{Distribución de las empresas transnacionales y las solicitudes de patentes en el Sur Global. Implicancias sobre el control de actividades centrales}

Como ya hemos referenciado en el apartado segundo y tercero del presente trabajo, los lugares de radicación de las ETs y de solicitudes de patentes pueden identificarse como indicadores indirectos del control de core activities. Así, el seguimiento de la cantidad de empresas transnacionales pertenecientes a países del Sur Global y de las patentes solicitadas en esas latitudes permite obtener proxis para analizar el tipo de actividad que desarrollan los distintos países periféricos dentro de la cadena de mercancías y reunir más información sobre las características de su estructura productiva.

El avance en el dominio de actividades de tipo centrales dentro de dichas cadenas, en desmedro de las actividades de tipo periféricas, se observa fundamentalmente en los países del Este asiático. En ellos, la capacidad del Estado para condicionar y direccionar la inversión de las ETs hacia sectores estratégicos permitió, en el marco de un particular contexto geopolítico al que se hiciera referencia con anterioridad, aprovechar favorablemente el dislocamiento producido por la nueva división internacional del trabajo y desarrollar actividades de creciente complejidad técnica y valor agregado (Wade, 2008; Chibber, 1999, 2008; Chang, 1993, 2004; Pempel, 1999).

Los gráficos 15 y 16 dan cuenta de ello. En el Gráfico 15, se puede observar la importancia de la participación de las empresas del Este asiático dentro de las 100 compañías no financieras más importantes del Sur Global, representando el $62 \%$ de las mismas. Las empresas de origen latinoamericano sólo representan el 9\% de las grandes ETs del Sur, situándose muy por debajo de la cantidad de grandes empresas del resto de los países asiáticos que no forman parte del centro dinámico y en el mismo nivel que el continente africano. En el Gráfico 16, puede advertirse el amplio diferencial que también existe entre ambos bloques en lo que refiere a la solicitud de patentes, sobre todo desde comienzos del presente siglo.

Gráfico 15

Cantidad de empresas no financieras dentro de las 100 principales de las economías periféricas (2008)

$$
\begin{aligned}
& \text { Este asiático } \quad \text { America Latina } \\
& \text { Resto de Asia } \quad \text { Africa }
\end{aligned}
$$

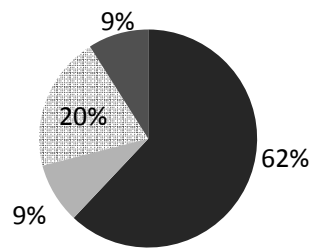

Fuente: Elaboración propia en base a de datos de UNCTAD-Erasmus University Data Base (2008).
Gráfico 16

Solicitud de patentes. (1985-2010)

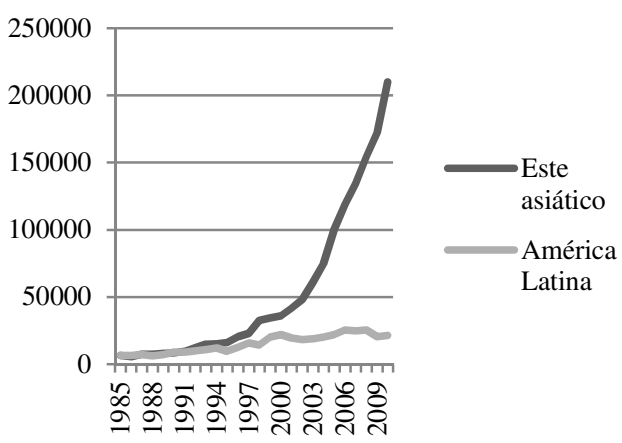

Fuente: Elaboración propia en base a de datos del Banco Mundial. 
Como resultado de las dimensiones analizadas en los puntos 3.2.1 y 3.2.2, se puede observar la existencia de asimetrías en los patrones de desenvolvimiento entre América Latina y los países dinámicos del Este asiático. Si bien ambos bloques evidencian un importante dinamismo dentro de la economía mundial en la última década, las diferencias cualitativas sobre las que sustentan su performance permiten advertir la existencia de una desigual participación en la generación y apropiación de los beneficios de la división internacional del trabajo, al mismo tiempo que dar cuenta de su diferencial tasa de crecimiento.

El incremento del valor agregado en las exportaciones desde el Este de Asia a América Latina y la relevante presencia de empresas transnacionales de origen asiático dentro de las más importantes del bloque, así como la creciente solicitud de patentes allí radicadas, resultan indicadores de una evolución de su estructura económica a partir de la sofisticación de la producción y el avance en el desarrollo y control de actividades centrales. En contrapartida, Latinoamérica continúa relacionándose a partir de su heterogénea y escasamente sofisticada estructura productiva, que hace persistir su forma dependiente de inserción (Cimoli et al., 2005).

De ese modo, la particular forma de relacionamiento que se establece entre el Este asiático y América Latina, a pesar de en términos agregados hacer converger al Sur con el Norte, pareciera indicar la persistencia de intercambios desiguales - sobre la base del desarrollo de actividades centrales o de mayor valorización, por el lado del Este asiático, y periféricas, por el latinoamericano que afectan la dinámica de crecimiento latinoamericano y su sostenibilidad, ahora bajo un esquema de relaciones Sur-Sur.

\section{Consideraciones finales}

El trabajo tiene como eje central la consideración del cambio geoeconómico global en el que destaca la consolidación de un nuevo centro dinámico de acumulación capitalista con epicentro en el Este asiático, sobre el que se sustenta la reciente emergencia del "Sur Global", representado ya hacia la primera década del presente siglo casi la mitad del producido mundial.

Se ha procurado explorar algunos de los alcances de dicha transformación, teniendo en cuenta la preservación de la estructura jerárquica del sistema- mundo capitalista, al mismo tiempo que aportando elementos para comprender cómo esa emergencia del "Sur Global" como un todo guarda, no obstante, en su interior, elementos que desafían la posibilidad de pensar la gestación de una dinámica más igualadora e inclusiva.

En relación a la preservación de la estructura, la historia del capitalismo ha evidenciado una tendencia estable en cuanto a su desenvolvimiento bajo un orden 
jerárquicamente desigual donde los cambios en cada una de las zonas que la conforman han sido excepcionales a lo largo de los cinco siglos de pervivencia de la economía-mundo. Según lo analizado en la primera parte del trabajo, la inclusión de los diferentes países en cada uno de dichos niveles jerárquicos tiene que ver con el grado de control de las distintas actividades y procesos dentro de una determinada cadena de mercancías. De ese modo, los países centrales presentan una mayor capacidad para ejercer dominio sobre las actividades que reportan mayores beneficios - las actividades centrales - y, por el contrario, los países periféricos quedan subsumidos al control de las actividades periféricas de la cadena.

Sin embargo, pese a la pervivencia de dicha estructura, ya desde la finalización de la Segunda Guerra Mundial, con el crecimiento japonés, pero más marcadamente a partir de la nueva división internacional del trabajo que se conformó a principios de los 70 , parece haberse consolidado un diferencial dinamismo de países tradicionalmente periféricos - que se agudizó en la primera década de este siglo - que habilita a plantear la posibilidad de alteración de dicha estructura de la mano de la progresiva emergencia del Sur Global.

A partir de la advertencia de ese proceso, en la segunda y tercera parte del trabajo, se procuró aportar elementos para dar luz sobre la posibilidad de plantear una alternativa más igualadora de funcionamiento del sistema global.

En la segunda parte, se analizó la dinámica de sofisticación que ha acompañado al proceso de desplazamiento del dinamismo de la reproducción capitalista hacia el Este asiático. Los países asiáticos han logrado un mayor protagonismo e incidencia en el orden mundial manifestado a través de su mayor participación en el PBI global y su creciente control sobre actividades centrales, lo que permite dar cuenta de un incipiente upgrading en su estructura productiva.

En la tercera parte, se resaltó, no obstante, que el Este asiático no es el único bloque dinámico dentro del "Sur Global"; otros grandes escenarios dentro de la periferia también han mostrado un importante crecimiento. Particularmente, centramos nuestra atención en el análisis de la evolución de América Latina en ese contexto de emergencia del Sur. A ese respecto, hemos podido advertir que, mientras el crecimiento latinoamericano ha tenido lugar sobre la base de una estructura productiva más "primarizada", los países del Este asiático se han mostrado capaces de incorporar progresivamente actividades de mayor sofisticación y valor, así como mayor participación a través de las ETs en las cadenas de mercancías, obteniendo, en consecuencia, desiguales beneficios del intercambio internacional - particularmente del intercambio Sur-Sur.

De ese modo, si bien la emergencia del Sur Global resulta innegable dada la participación creciente de los países históricamente periféricos en la generación 
y apropiación de riqueza mundial, la generación de una estructura menos jerárquica lejos está de aparecer como una realidad inminente. Por el contrario, parecería estar teniendo lugar la configuración de nuevas formas de subordinación, ahora dentro del mismo Sur.

La cristalización - o reversión - de ese esquema desigualador podría depender, especialmente, de dos aspectos. Por un lado, de la evolución de la economía china en el control de las actividades centrales de las cadenas de mercancías, teniendo como limitante, para ello, entre otros aspectos, la indicada presencia de un Estado que aún no reúne las características desarrollistas y que ya por falta de coherencia interna, reclutamiento meritocráctico, falta de autonomía o de capacidad de enraizamiento en la sociedad puede llegar a condicionar la estrategia de crecimiento sobre la base del up grade de su estructura productiva. Por otro lado, de la capacidad de respuesta que el resto de los Estados de la periferia global pueda proporcionar para integrarse de manera cualificada a dichas cadenas o generar otras que no lo posicionen necesariamente como "socio subalternos y periféricos". Dentro de este último aspecto se inscribe el principal desafío de América Latina en los próximos años.

\section{Referencias bibliográficas}

AKYUZ, Y.; CHANG, H.; KOZUL-WRIGHT, R. New perspective on East Asia development. Journal of Development Studies, v. 34, n. 6, p. 4-36, 1998.

AMSDEN, A. The rise of the rest: challenges of the West from late-industrializing economies. New York: Oxford University Press, 2001.

Goodbye dependency theory, hello dependency theory. Studies in Comparative International Development, v. 38, n. 1, p. 32-38, 2003.

ARCEO, E. El impacto de la globalización en la periferia y las nuevas y viejas formas de la dependencia en América Latina. Cuadernos del Cendes, v. 22, n. 60, p. 25-61, 2005.

ARRIGHI, G. El largo siglo XX. Madrid: Akal, 1999.

ARRIGHI, G.; DRANGEL, J. The stratification of the world-economy: an exploration of the semiperipheral zone. Review, v. X, n. 1, p. 9-74, 1986.

ARRIGHI, G., SILVER, B.; BREWER, B. Industrial convergence, globalization, and the persistence of north-south divide. Studies in Comparative International Development, v. 38. n. 1, p. 3-31, 2003.

BEESON, M. Developmental states in East Asia: a comparison of the Japanese and Chinese experiences. Asian Perspective, v. 33, n. 2, p. 5-39, 2009.

BERRETTONI, D.; POLONSKY, M. Evolución del comercio exterior argentino en la última década: origen, destino y composición. Revista del CIE, n. 19, p. 80-99, 2011. 
BERGESEN, A.; SAHOO, C. Evidence of the decline of american hegemony in world production. Review, v. 8, n. 4, p. 595-611, 1985.

BORON, A. Teoría(s) de la dependencia. Revista Realidad Económica, n. 238, p. 20-43, 2008.

BRESLIN, S. Power and production: rethinking China's global economic role. Review of International Studies, n. 31, p. 735-753, 2005.

BRESSER-PEREIRA， L. C.; GALA， P. Macroeconomia estructuralista do desenvolvimento. Revista de Economía Política, v. 30, n. 4 (120), p. 663-686, 2010.

CEPAL. La inversión extranjera directa en América Latina y el Caribe. Santiago de Chile, 2010.

CEPAL. Panorama de la inserción internacional de América Latina y el Caribe 20112012. Santiago de Chile, 2012.

CEPAL. Panorama de la inserción internacional de América Latina y el Caribe 20102011. Santiago de Chile, 2011a.

CEPAL. Estudio Económico de América Latina y el Caribe 2010-2011. Santiago de Chile, 2011b.

CHANG, H. Regulation of foreign investment in historical perspective. European Journal of Development Research, v. 16, 2004.

The political economy of industrial policy in Korea. Cambridge Journal of Economics, v. 16, n. 2, p. 131-157, 1993.

CHIBBER, B. ¿Revivir el Estado Desarrollista? El mito de la burguesía nacional. Documentos y Aportes en Administración Pública y Gestión Estatal, n. 11, p. 7-34, 2008.

Building a developmental state: the Korean case reconsidered. Politics \& Society, v. 27, n. 3, p. 309-346, 1999.

CIMOLI, M., PORCILE, G., PRIMI, A., Y VERGARA, S. Cambio estructural, heterogeneidad productiva y tecnología en América Latina. In: CIMOLI, M. (Ed.). Heterogeneidad estructural, asimetrías tecnológicas y crecimiento en América Latina. Santiago de Chile: CEPAL, 2005.

DABAT, A. La crisis financiera en Estados Unidos y sus consecuencias internacionales. Problemas del Desarrollo, v. 40, n. 157, p. 39-74, 2009.

; MELO MARTÍNEZ, O. La crisis histórico estructural de Estados Unidos y sus consecuencias mundiales. Economía Informa, n. 352, p.7-19, 2008.

; LEAL, P. Declinación de Estados Unidos: contexto histórico mundial. Problemas del Desarrollo, v. 174, n. 44, Jul./Sept. 2013. 
DICKEN, P. Global shift, fifth edition: mapping the changing contours of the world economy. New York: Guilford Press, 2007.

DUNFORD, M.; LI, L. Chinese spatial inequalities and spatial policies. Geography Compass, 4/8, p. 1039-1054, 2010.

EVANS, P. Embedded autonomy: states and industrial transformation. Princeton: Princeton University Press, 1995.

FIORI, J. O sistema interestatal capitalista no início do século XXI. In: MEDEIROS, C.; SERRANO, F.; FIORI, J. O mito do colapso do poder americano. Sao Paulo: Editora Record, 2008.

FRÖBEL, F.; HEINRICHS, J.; KREYE, O. The tendency towards a new international division of labor: the utilization of a world-wide labor force for manufacturing oriented to the world market. Review, v. 1, n. 1, p. 73-88, 1977.

GEREFFI, G. Las cadenas productivas como marco analítico para la globalización. Problemas del Desarrollo, v. 32, n. 125, p. 9-37, 2001.

GLASSMAN, J. The geo-political economy of global production networks. Geography Compass, v. 5, n. 4, p. 154-164, 2011.

HARDT, M.; NEGRI, A. Empire. Cambridge: Harvard University Press, 2000.

HARRIS, N. The end of the Third World. Newly industrializing countries and the decline of an ideology. Harmondsworth: Penguin Books, 1986.

HARVEY, D. El nuevo imperialismo. Madrid: Akal, 2004. Spaces of hope. Edinburgh: Edinburgh University Press, 2000.

HIKINO, T.; AMSDEN, A. La industrialización tardía en perspectiva histórica. Desarrollo Económico, v. 35, n. 137, p. 3-34, 1995.

HOPKINS, T.; WALLERSTEIN, I. Commodity chains in the world-economy prior to 1800. Review, v. 10, n. 1, p. 157-170, 1986.

HUMPHREY, J.; SCHMITZ, H. Governance and upgrading: linking industrial cluster and global value chain research. IDS Working Paper, n. 120, 2000.

JOHNSON, C. Political institutions and economic performance: the government-business relationship in Japan, South Korea and Taiwan. In: DEYO, F. C. (Ed.). The political economy of the new Asian industrialism. Ithaca: Cornell University Press, 1987.

KAPLINSKY, R. Spreading the gains from globalization: what can be learn from value chain analysis?. IDS Working Paper, n. 110, 2000.

KOHLI, A. Estado y desarrollo económico. Documentos y Aportes en Administración Pública y Gestión Estatal, n. 12, p. 7-29, 2009. 
LEMOINE, F.; ÜNAL-KESENCI, D. Assembly trade and technology transfer: the case of China. World Development, v. 32, n. 5, p. 829-850, 2004.

LI, L.; DUNFORD, M.; YEUNG, G. International trade and industrial dynamics: geographical and structural dimensions of Chinese and Sino-EU merchandise trade. Applied Geography, n. 32, p. 130-142, 2012.

MADDISON A. The world economy. Washington, DC: OECD Publishing, 2006.

MAHUTGA, M. The persistence of structural inequality? A network analysis of international trade, 1965-2000. Social Forces, v. 84, n. 4, p. 1863-1889, 2006.

MANN, M. The autonomous power of the state: its origins, mechanisms and results. European Journal of Sociology, n. 25, p. 185-213, 1984.

MCMICHAEL, P. Incorporating comparisons within a world-historical perspective: an alternative comparative method. American Sociological Review, v. 55, n. 3, p. 385-397, 1990.

MINTZ, S. The so-called world system: local initiative and local response. Dialectical Anthropology, n. 2, p. 253-70, 1977.

MEDEIROS, C. Desenvolvimento econômico e ascensao nacional: rupturas e transições na Rússia e na China. In: MEDEIROS, C.; SERRANO, F.; FIORI, J. O mito do colapso do poder americano. Sao Paulo: Editora Record, 2008.

PALMA, G. Why has productivity growth stagnated in most Latin American countries since the neo-liberal reforms? The economic consequences of a rentier-dominated power structure and a narcissistic ideology. Cambridge Working Papers in Economics, 130, 2010.

PALMA, G. Latin America during the second half of the twentieth century: from the "age of extremes" to the age or "end-of-history" uniformity. In: CHANG, H-J. (Ed.). Rethinking development economics. London: Anthem Press, 2003.

PEMPEL, T. J. The developmental regime in a changing world economy. In: WOOCUMMINGS, M. (Ed.). The developmental state. New York: Cornell University Press, 1999.

PÉREZ, C. Technological revolutions, paradigm shifts and socio-institutional change. In: REINERT, E. (Ed.). Globalization, economic development and inequality: an alternative perspective. United Kingdom: Edward Elgar, 2004.

Technological revolutions and techno-economic paradigms. Working Papers in Technology Governance and Economic Dynamics. Tallinn: The Other Canon Foundation, Norway and Tallinn University of Technology, 2009

ROBINSON, W.; HARRIS, J. Towards a global ruling class? Globalization and the transnational capitalist class. Science and Society, v. 64, n. 1, p. 11-54, 2000. 
ROSEBERRY, W. Anthropologies and histories, essays in culture, history, and political economy. New Brunswick: Rutgers University Press, 1989.

SÁNCHEZ ANCOCHEA, D. Inserción externa, heterogeneidad estructural y globalización en América Latina. Institute for the Study of the Americas, Universidad de Londres, 2005.

SANTISO, J. La emergencia de las multilatinas. Revista de la CEPAL, n. 95, p. 7-30, 2008.

SASSEN, S. Ciudades en la economía global: enfoques teóricos y metodológicos. Eure, v. XXIV, n. 71, p. 5-25, 1998.

SCHUMPETER, J. Capitalism, socialism, \& democracy. London: Allen \& Unwin, 1954.

SKOCPOL, T. Wallerstein's world capitalist system: a theoretical and historical critique. American Journal of Sociology, v. 82, n. 5, p. 1075-1090, 1977.

TOMICH, D. Slavery in the circuit of sugar. Baltimore: The John Hopkins University Press, 1990.

World market and american slavery: problems of historical method. Paper presented at the conference on Els espais del mercat, Second International Local History Colloquy, University of Valencia, Spain, Apr. 2001.

TOMICH, D. World of capital/Worlds of labor: a global perspective. In: HALL J. R. (Ed.). Reworking class. Ithaca: Cornell University Press, 1997.

WADE, R. Reubicando al Estado: lecciones de la experiencia de desarrollo del Este asiático. Documentos y Aportes en Administración Pública y Gestión Estatal, n. 10, p. 7-28, 2008 .

WALLERSTEIN, I. The modern world-system: capitalist agriculture and the origins of the European world-economy in the sixteenth century. New York; London: Academic Press, 1974.

Capitalismo histórico y movimientos antisistémicos. Un análisis de sistemasmundo. Madrid: Akal, 2004

WEISS, L. Introduction: bringing domestic institutions back in. In: WEISS L. (Ed.). States in the global economy. Bringing domestic institutions back. Cambridge: Cambridge University Press, 2003.

WOLF, E. Europe and the people without history. Berkeley: University of California Press, 1982.

WOO-CUMINGS, M. (Ed.). The developmental state. New York: Cornell University Press, 1999. 


\section{Bases de datos consultadas}

Banco Mundial, www.bancomundial.org. Fecha de acceso: Marzo, 2012.

Forbes, www.forbes.com. Fecha de acceso: Marzo, 2012.

Fortune, money.cnn.com/magazines/fortune. Fecha de acceso: Marzo, 2012.

Organización Mundial del Comercio (OMC), www.wto.org. Fecha de acceso: Marzo, 2012.

United Nation Conference on Trade and Development (UNCTAD),

www.unctadstat.unctad.org. Fecha de acceso: Marzo, 2012.

United States International Trade Commission (USITC), www.usitc.gov. Fecha de acceso: Marzo, 2012.

USPTO Statistics Database, October 2012. 